\title{
The Economic Situation Analysis of the Impact for Cancelling Drug Addiction on Public Hospitals' Operations*
}

\author{
Yu Wang \\ The First Affiliated Hospital of Hebei North University, Zhangjiakou, China \\ Email:wy8421@163.com
}

How to cite this paper: Wang, Y. (2021). The Economic Situation Analysis of the Impact for Cancelling Drug Addiction on Public Hospitals' Operations. Modern Economy, 12, 1073-1081.

https://doi.org/10.4236/me.2021.126055

Received: May 10, 2021

Accepted: June 15, 2021

Published: June 18, 2021

Copyright $\odot 2021$ by author(s) and Scientific Research Publishing Inc. This work is licensed under the Creative Commons Attribution International License (CC BY 4.0).

http://creativecommons.org/licenses/by/4.0/

\begin{abstract}
Objective: Investigation of the impact of the reform of urban public hospitals in cancelling drug price addition on public hospitals' operations and patient personal burdens, providing data support for the comprehensive reform of urban public hospitals. Methods: Using Excel 2007, the overall operation of the hospital, the workload of medical staff in the internal and external departments, the proportion of medicines, and the burden of medicines for patients were analyzed before and after the cancellation of drug sales in a public hospital. Results: The cancellation of drug price additions had little effect on the outpatient visits of the hospital, and had a greater impact on the hospital's income structure and patient's consumption structure. Conclusion: Simply relying on the cancellation of drug price addition cannot effectively adjust the structural contradiction of medical service prices in the reform of public hospitals in the urban areas. The transformation of medical institutions from "drug dependent doctors" to "doctors dependent doctors" requires the strengthening of hospital internal management, so that supporting medicine price reforms will ultimately improve the overall quality and efficiency of the hospital.
\end{abstract}

\section{Keywords}

Cancelling Drug Price Addition, Medical Price Reform, The Reform of Urban Public Hospitals, Drug Dependent Doctors

\section{Introduction}

At the end of 2016, the Chinese government began to reform the medical and health system, and made many decisions to adjust the income of medical institutions, which affected people's medical consumption. According to the Party *Science and Technology Agency item number: 205576159D. 
central, State Council, Provincial Party Committee and Government document "Opinions of the CPC Hebei Provincial Committee and the People's Government of Hebei Province on the Comprehensive Reform of Public Hospitals" (Hebei Provincial Government Document No. 201619), "Comprehensive Reform Implementation Plan of Public Hospital in Zhangjiakou” (Zhangjiakou Municipal Government Document No. 201622). Cancelling drug price addition and breaking the mechanism of "doctors depend on drug" will be an important part of the medical reform. That is a direct manifestation. Through comparative analysis of the three years of operation data before and after the reform of the only third-grade class-A hospital in Zhangjiakou city (The First Affiliated Hospital of Hebei North University). Comparative analysis of changes in income, medical staff workload and patient consumption structure of public hospitals before and after drug price addition cancellation; describe the effect and effectiveness of the reform on public hospitals.

\section{Data and Methods}

In the fourth quarter of 2016, it was launched the comprehensive reform in public hospitals of Zhangjiakou, The main content is to change the revenue compensation of public hospitals from three channels of service charge, drug addition and government subsidy to two channels of service charge and government subsidy. We should increase the medical and health expenses reasonably by abolishing the mechanism of "supplementing medicine with medicine" and adjusting the price of medical services. This paper takes the business data before and after the reform as the analysis object, and the time is 2015, 2016 and 2017, respectively. By comparing the change range of workload, drug proportion and other data in the same period and making statistics, the results of the pharmaceutical price reform of public hospitals after the reform are obtained.

The research methods: Excel 2007 was used to organize and input data for statistical and descriptive analysis.

\section{Result}

\subsection{Comparison of Overall Economic Indicators of Hospitals before and after the Reform (Unit: Yuan)}

Income, expenditure and balance of hospitals all showed a growth trend (Table 1). Income and expenditure of hospitals showed a sustained growth trend, and slowed down slightly. The balance showed an inverse growth trend after the health care reform in 2016, the growth rate was $-18.15 \%$ (Figure 1). The average outpatient cost and the average daily cost per bed also showed a slow growth trend after the health care reform in 2017, which was 12.14 yuan higher than the outpatient cost before the health care reform, but the increase was not significant; the average daily cost per bed in hospital decreased by $8.04 \%$ compared with the previous year's growth rate.

Table 1 for details: 
Table 1. Economic indicators of hospitals before and after the reform.

\begin{tabular}{|c|c|c|c|c|c|}
\hline & 2015 & 2016 & 2017 & $\begin{array}{l}\text { 2015-2016 } \\
\text { growth rate }\end{array}$ & $\begin{array}{l}\text { 2016-2017 } \\
\text { growth rate }\end{array}$ \\
\hline Medical income & $733,522,530.7$ & $914,981,291.4$ & $1,017,646,037$ & $24.74 \%$ & $11.22 \%$ \\
\hline $\begin{array}{c}\text { Medical } \\
\text { expenditure }\end{array}$ & $677,826,529.9$ & $811,466,929.1$ & $932,921,362.9$ & $19.72 \%$ & $14.97 \%$ \\
\hline balance & $55,696,000.8$ & $103,514,362.3$ & $84,724,673.93$ & $85.86 \%$ & $-18.15 \%$ \\
\hline $\begin{array}{l}\text { The average } \\
\text { outpatient } \\
\text { cost per day }\end{array}$ & 336.85 & 363.4 & 375.54 & $7.88 \%$ & $3.34 \%$ \\
\hline (drugs) & 172.2 & 186.29 & 178.8 & $8.18 \%$ & $-4.02 \%$ \\
\hline $\begin{array}{l}\text { The average } \\
\text { inpatient daily } \\
\text { cost per bed }\end{array}$ & 1225.28 & 1380.66 & 1444.71 & $12.68 \%$ & $4.64 \%$ \\
\hline (drugs) & 604.8 & 671.66 & 595.87 & $11.05 \%$ & $-11.28 \%$ \\
\hline
\end{tabular}

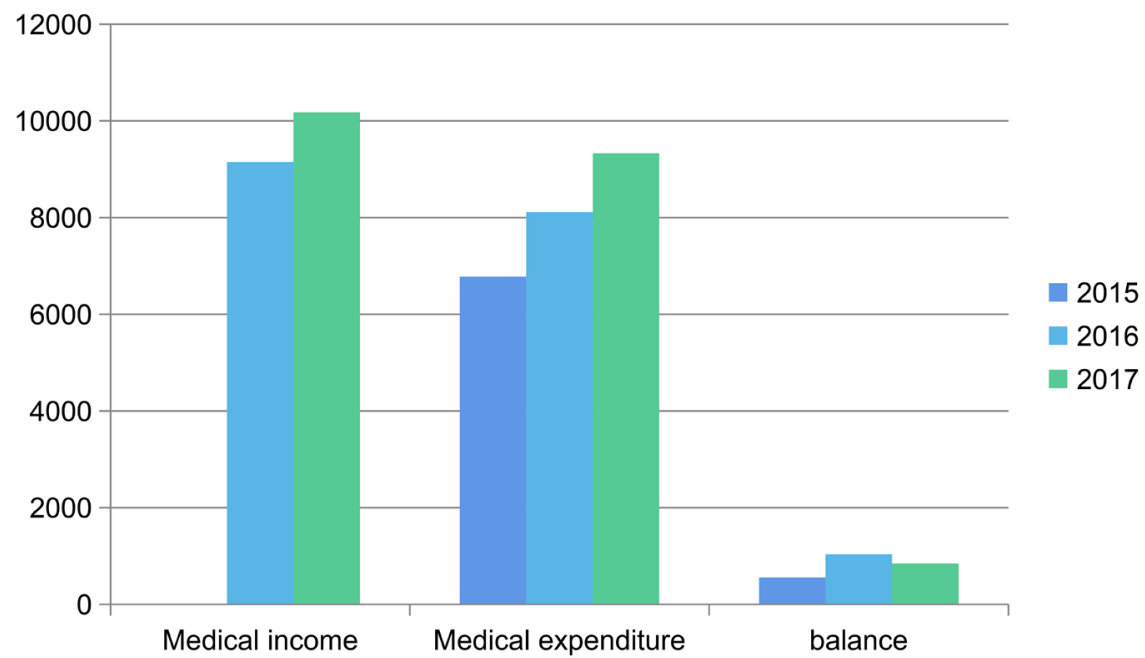

Figure 1. The chart for Income, expenditure and balance of hospitals, the unit of Y-axis is ten thousand yuan.

\subsection{The Impact of Hospital Workload}

Outpatient statistics include general clinics and specialist clinics. Data before and after the reform show that the workload of internal medicine and surgical outpatient service in hospitals tends to be stable after cancelling drug price addition. Emergency workload changed little, outpatient workload growth rate increased a lot, through data comparison, the growth rate of convenience clinic in 2016-2017 increased from $5.07 \%$ to $16.7 \%$ compared with the same period, the increase is obvious. The results are shown in Table 2.

\subsection{Influences of Income Structure of Outpatient and Inpatient Services in Hospitals}

After cancelling drug price addition, outpatient income increased, and the pro- 
portion of inspection, laboratory and drug revenue reached $87 \%$ in the past three years, maintaining a stable state. The proportion of drug revenue declined slightly, but it was still the highest, and the operation income increased rapidly, but the overall proportion was low, see Table 3 for details. After the medical reform of the hospitalization income, the income of drugs for cancelling drug price addition showed a downward trend, reaching 5.39\%, and the proportion declined significantly. Although the proportion of nursing and consultation income is small, the increase is obvious. See Table 4 for details. The proportion of medicine in outpatient and inpatient incomes has declined, and the proportion of medicine in internal and external medicine has declined. The proportion of medicine in internal medicine has always been higher than that in surgical medicine. Details are shown in Table 5.

Table 2. Statistical table of the workload of internal medicine and surgery clinics (unit: person).

\begin{tabular}{cccccc}
\hline & 2015 & 2016 & 2017 & $\begin{array}{c}2015-2016 \\
\text { growth rate }\end{array}$ & $\begin{array}{c}2016-2017 \\
\text { growth rate }\end{array}$ \\
\hline Internal medicine & 195,497 & 245,294 & 246,136 & $25.47 \%$ & $0.34 \%$ \\
surgery & 164,031 & 185,003 & 192,443 & $12.79 \%$ & $4.02 \%$ \\
convenience clinic & 96,246 & 101,128 & 118,018 & $5.07 \%$ & $16.70 \%$ \\
Emergency & 16,341 & 18,983 & 22,185 & $16.17 \%$ & $16.87 \%$ \\
Total & 472,115 & 550,408 & 578,782 & $16.58 \%$ & $5.16 \%$ \\
\hline
\end{tabular}

Table 3. Outpatient income structure growth table.

\begin{tabular}{cccccc}
\hline Outpatient income items & 2015 & 2016 & 2017 & $\begin{array}{c}2015-2016 \\
\text { growth rate }\end{array}$ & $\begin{array}{c}2016-2017 \\
\text { growth rate }\end{array}$ \\
\hline Registered & $0.30 \%$ & $0.27 \%$ & $0.27 \%$ & $9.29 \%$ & $6.52 \%$ \\
Consultation & $1.49 \%$ & $1.43 \%$ & $1.35 \%$ & $12.73 \%$ & $4.20 \%$ \\
Inspection & $22.87 \%$ & $22.70 \%$ & $24.31 \%$ & $16.97 \%$ & $17.80 \%$ \\
laboratory & $13.83 \%$ & $14.16 \%$ & $15.94 \%$ & $20.67 \%$ & $23.77 \%$ \\
Treatment & $6.95 \%$ & $7.04 \%$ & $7.08 \%$ & $19.29 \%$ & $10.69 \%$ \\
Surgery & $0.35 \%$ & $0.34 \%$ & $0.58 \%$ & $16.84 \%$ & $85.52 \%$ \\
Hygienic material & $2.85 \%$ & $2.58 \%$ & $2.66 \%$ & $7.02 \%$ & $13.36 \%$ \\
Drug & $51.12 \%$ & $51.26 \%$ & $47.61 \%$ & $18.18 \%$ & $2.15 \%$ \\
Others & $0.25 \%$ & $0.21 \%$ & $0.20 \%$ & $-0.51 \%$ & $2.98 \%$ \\
\hline
\end{tabular}

Table 4. Inpatient income structure growth table.

\begin{tabular}{cccccc}
\hline Inpatient income items & 2015 & 2016 & 2017 & $\begin{array}{c}2015-2016 \\
\text { growth rate }\end{array}$ & $\begin{array}{c}2016-2017 \\
\text { growth rate }\end{array}$ \\
\hline Bed & $3.67 \%$ & $3.35 \%$ & $3.13 \%$ & $15.96 \%$ & $4.50 \%$ \\
Consultation & $0.44 \%$ & $0.37 \%$ & $1.02 \%$ & $7.10 \%$ & $208.20 \%$ \\
Inspection & $10.00 \%$ & $9.13 \%$ & $10.21 \%$ & $15.88 \%$ & $24.83 \%$ \\
\hline
\end{tabular}




\section{Continued}

\begin{tabular}{cccccc}
\hline Laboratory & $13.03 \%$ & $12.61 \%$ & $13.63 \%$ & $22.94 \%$ & $20.63 \%$ \\
Treatment & $6.00 \%$ & $5.88 \%$ & $5.92 \%$ & $24.37 \%$ & $12.43 \%$ \\
Surgery & $5.01 \%$ & $4.64 \%$ & $5.47 \%$ & $17.48 \%$ & $31.73 \%$ \\
Nursing & $0.61 \%$ & $0.51 \%$ & $2.55 \%$ & $6.59 \%$ & $458.52 \%$ \\
Hygienic material & $10.98 \%$ & $14.12 \%$ & $16.09 \%$ & $63.27 \%$ & $27.21 \%$ \\
Drug & $49.36 \%$ & $48.65 \%$ & $41.24 \%$ & $25.16 \%$ & $-5.39 \%$ \\
Others & $0.91 \%$ & $0.76 \%$ & $0.73 \%$ & $6.34 \%$ & $7.48 \%$ \\
\hline
\end{tabular}

Table 5. The situation of drug revenue proportion of internal medicine and surgical department.

\begin{tabular}{cccccc}
\hline $\begin{array}{c}\text { drug revenue } \\
\text { proportion }\end{array}$ & 2015 & 2016 & 2017 & $\begin{array}{c}2015-2016 \\
\text { growth rate }\end{array}$ & $\begin{array}{c}2016-2017 \\
\text { growth rate }\end{array}$ \\
\hline internal medicine & $48.81 \%$ & $49.66 \%$ & $44.15 \%$ & $0.85 \%$ & $-5.51 \%$ \\
surgical & $45.09 \%$ & $45.76 \%$ & $40.02 \%$ & $0.67 \%$ & $-5.74 \%$ \\
Total & $46.95 \%$ & $47.71 \%$ & $42.06 \%$ & $0.76 \%$ & $-5.63 \%$ \\
\hline
\end{tabular}

\section{Discussion}

1) To cancel drug price addition on public hospitals, the proportion of drug revenue in public hospitals has been declined gradually, and the cost structure of departments has been changed.

Economic operating income, expenditure, and balance are still growing, but profit are showing negative growth, outpatient and inpatient drug revenue all declined. From the departmental income statistics, the proportion of incomes of internal drug and surgical drug had been reduced. The hospitals management included the proportion of drug revenue into the performance indicators of the department, and linked it to the income of the department to achieve the purpose of reducing the proportion of drug revenue. However, drug revenue are still the main component of medical expenses of patients, and other proportions such as treatment costs are still low (Gong et al., 2017). The high drug revenue proportion are the main reason of the negative growth of the hospitals. So the applied policy of cancelling drug price addition made the policy-related losses of hospitals and drug revenue are still the main component of medical expenses. It is shows that the effect of cancelling drug price addition is not significant (Chen \& Huang, 2015).

Public hospital reformed and cancelled drug price addition, the hospitals' revenue compensation from three channels of service charge, drug price addition and government subsidy is changed to from two channels of the service charge and government subsidy. The total price adjustment of medical services is mainly based on the degree of declining of hospitals' income after cancelling drug price addition (Jin et al., 2016). For adjusting the hospitals' income structure, the government should issue and implement policy according to differenc- 
es local levels. For example, Zhejiang Province government proposed to compensate through the adjustment of the price structure of medical services reaching $90 \%$ of the loss, and the other $10 \%$ was solved through the refined management of the hospitals (Ma et al., 2015). According to the principle of capacity control and structural adjustment, the Jiangning District Government of Nanjing proposed to compensate reaching $70 \%$ through the adjustment of the price structure of medical services, $20 \%$ from the financial compensation, and $10 \%$ from the hospital through improving management level (Huang \& Li, 2014). The Zhangjiakou Municipal Government promoted the reform of public hospitals, adjusted the price structure of medical technology services to make the loss compensated reaching $80 \%, 10 \%$ solved by financial compensation, $10 \%$ digested by the hospitals (Zhangjiakou Municipal Government Document No. 201622). So, in breaking the mechanism of "doctors depend on drug", the reform of medical technology service prices should be implemented in parallel with the cancelling drug price addition. Through outpatient and inpatient income structure statistics, the income of medical consultation, surgery and nursing increased significant. This shows that the medical services price reform tends to reflect the value of medical staff services. But the proportion of medical consultation, surgery, and nursing is not high. The proportion of the cost of medical consultation, surgery, nursing, treatment, etc of hospital income only reaching $9.01 \%$ in 2016 and $14.96 \%$ in 2017. It can not reach the proportion of the profit by saling the drug before cancelling drug price addition.

The number of convenience clinic and emergency patients has been growing which made the sale of the drug increased always.

After cancelling drug price addition, the patients took the medicine in through registering in convenience clinic. The register fee of convenience clinic is cheap, the hospital' drugs are sold zero-profit, so many patients choose to spend the cheap register fee in the hospital to buy drugs. The more the drugs are sold, the more profit the hospital lost. It could not fully reflect the value of the third-grade class-A hospital. At the same time, over-sold drugs in the third-grade class-A hospital is not conducive to reduce the proportion of drugs revenue in hospitals. Although the number of emergency patients has continued to grow, the growth rate is relatively stable.

2) The patient's average costs have increased slightly and the cost structure has changed.

There is little change in the cost per person per day for outpatients and the inpatients whose drug costs all declined. And after cancelling drug price addition, the proportion of incomes of internal drug and surgical drug had been all reduced. The increased costs per person per day for inpatients aren't obvious just as the surgery costs and the care costs, but the consumption structure had been changed. This is consistent with the policy of comprehensive reform of medical prices. The proportion of drug revenue in hospitals has been declined, but the average cost of outpatient and inpatient has not been reduced. So the ex- 
ecuted policies just as cancelling drug price addition, shorting average length of stay in hospitals affected the hospitals' incomes directly and truned the lost revenues into the burden on patients.

\section{Suggestion}

1) Strengthen government action and invest financial subsidies. The tertiary hospitals could open convenience clinics to save patients' time effectively for prescribing and inspection. However, the more medicines are sold by hospitals after cancelling drug price addition, the more labor costs are consumed, the more income losses. So the losses should also be considered by government when the compensation policy is made. The government should take the role of the investor through public expenditure, and increase the investment in the health industry, and guarantee the basic medical care accessibility. The government should not pass on the public welfare responsibility to public hospitals and medical service providers (Zhou \& Zou, 2012).

2) Hospitals should increase registration fee according to different levels of the hospitals and improve the income structure. According to the state's tiered pricing management requirements, hospitals should increase hierarchical diagnosis and treatment fee (Shen, 2012). Currently, the price structure of medical services has not been adjusted entirely. According to the classification criteria, government should consider adjusting the gap between the tertiary hospitals and the primary and secondary hospitals, relaxing the adjustment space, and implementing a certain adjustment standard. Such as public hospitals of Shenzhen cancelled drug price addition and increased hierarchical diagnosis and treatment fee. And the increased part could be paid directly by medical healthcare insurance fund. Based on the original charges the different price could be increased according to different levels of public hospitals (Peng et al., 2014). But the registration fees of more provinces and cities hospitals increased the same level what can't reflect the role of graded diagnosis and treatment. Therefore, the government should consider adjusting the price of the registration fee and increase the registration fee of the general outpatient and specialist clinics of the tertiary hospitals. So that the value of medical staff could be further reflected.

3) Enhance the internal drive of "doctors depend on doctors" and highlight the value of the services of medical staff. The price structure of medical services has also been adjusted after cancelling drug price addition, but on current the value of technical labor force is still underestimated (Liu \& Lv, 2017). The government should grasp the opportunity of canceling drug price addition and adjust medical service prices, tease out medical service price items comprehensively, rationalize the relationship between medical service prices gradually, increase those projects' costs which reflect the value of medical staff, and establish a comprehensive, scientific and reasonable medical service price system finally (Wei et al., 2017). Income structure should highlight the value of medical staff's technical services, which not only requires a reasonable price system for medical 
services which is established by the external government, but also requires the preferential policy in terms of price charges and medical insurance subsidies, it also requires hospitals to strengthen internal management (Wei et al., 2017). Hospitals should establish scientific workload performance and compensation management system for embodying the labor value. The system should highlight accounting performance of medical staff in the department, the remuneration is calculated through the system should be linked to performance appraisal and reflect the value of medical staff's technical labor, enhance the enthusiasm of medical staff and improve the hospitals' efficiency. Therefore, through strengthening the internal management of the hospitals based on the drug price reform, the hospitals could improve the working quality and efficiency ultimately.

In conclusion, the reform of the medical and health system is a good thing for the people, which can make the cost of medical treatment lower. But for hospitals, it needs a transitional period. During this transitional period, the government should give subsidies and take some forms to promote the reform of hospitals smoothly.

\section{Conflicts of Interest}

The author declares no conflicts of interest regarding the publication of this paper.

\section{References}

Chen, T. Q., \& Huang, X. G. (2015). Effects of Medical Pricing Reform in County Level Public Hospital on Hospitalization Expenses in Jiangsu. Medicine and Society, 28, 12-15.

Gong, X., Pan, J. C., Zhu, L. et al. (2017). The Impact of Drug Price Reform on the Economic Operation Efficiency of Urban Public Hospitals. Chinese Hospital Management, $429,6-8$

Huang, H. M., \& Li, L. (2014). Effect of Health Care Price Reform on Medical Expenditure and Cost of Health Insurance: An Analysis of County Hospitals in Nanjing, Jiangsu Province. Chinese Journal of Health Policy, 7, 56-62.

Jin, C. L., Wang, W., Gong, L. et al. (2016). Reform Strategy and Price Adjustment Progress in Medical Service Items in China. Chinese Health Resources, 19, 83-86.

Liu, Q. W., \& Lv, D. B. (2017). Analysis on the Effects of Drug Price Reform of Hospitalization Expenses in Public Hospitals. Modern Hospital Management, 15, 62-65.

Ma, W. H., Wang, Z., Sun, J. W. et al. (2015). Exploration and Practice of the Public Hospital Medical Service Price Reform in Zhejiang Province. Chinese Journal of Health Policy, 8, 19-23.

Peng, Y., Li, F., \& Jin, C. L. (2014). Practice and Consideration of Medical Service Price Adjustment Based on the Cancellation of Drug Markup. Chinese Health Resources, 17, 419-421.

Shen, H. L. (2012). Medical Insurance Get the First Implement of Comprehensive Reform the Medical \& Drugs Separation at Public Hospitals in Shenzhen. Chinese Medical In surance, 47, 24-26.

Wei, J. C., Chi, W. Y., Xu, D. C. et al. (2017). Changes of the Internal Operation Mechan- 
ism and Improvement of Performance of Public Hospitals without Drug Price Addition. Chinese Journal of Hospital Administration, 33, 98-101.

Zhou, L. L., \& Zou, H. L. (2012). Discussion on Compensation Mechanism of Public Hospital after Cancelling Drug Price Addition. Chinese Pharmacy, 23, 9-11. 